\title{
FRANCISCO VALLES COVARRUBIAS: O GALENISMO RENASCENTISTA DEPOIS DE ANDREAS VESALIUS
}

João Madeira*

RESUMO - Francisco Valles, também conhecido como "El Divino Valles", foi provavelmente o maior médico espanhol da Renascença e sucedeu a André Vesálio, a quem conheceu pessoalmente, como médico de câmara de Felipe II da Espanha. Formado em Alcalá, deixou inúmeras obras, incluindo o influente Controversiarum medicarum et philosophicarum. A importância da contribuição de Valles para o debate sobre o número, as funções e a localização dos sentidos internos em Aristóteles e em Galeno é atestada pela apreciação que recebeu de Pedro da Fonseca e pela sua relevância para o estudo da história da filosofia e da anatomia, na antiguidade, no Renascimento e na escolástica.

PALAVRAS-CHAVE - Galeno. Anatomia. Sentidos internos. Francisco Valles. Segunda escolástica.
ABSTRACT - Francisco Valles, also known as 'The Divine Valles', was most probably the greatest Spanish physician of the Renaissance and succeeded Andreas Vesalius, whom he knew well, as the personal doctor of Philip II of Spain. Valles studied in Alcalá and wrote several works, among which the influential Controversiarum medicarum et philosophicarum. The importance of Valles's contribution to the debate concerning the number, the specific tasks, and the localization of the internal senses in Aristotle and in Galen is attested by Pedro da Fonseca's appreciation of his contribution and by the relevance of Valles's works to the study of the history of philosophy and of anatomy, in antiquity, in the Renaissance and in scholasticism.

KEY WORDS - Galen. Anatomy. Internal senses. Francisco Valles. Second scholasticism.

\section{Introdução}

Francisco de Valles nasceu em 04 de outubro de 1524, em Covarrubias, província de Burgos, Castela e Leão, Espanha. Era filho primogênito de Francisco de Valles e de Brianda de Lemos e, por isso, recebeu educação

* Pós-doutorando na Faculdade de Filosofia, Ciências e Letras de Ribeirão Preto Universidade de São Paulo, bolsista FAPESP.

\begin{tabular}{|l|l|l|l|l|l|} 
VERITAS & Porto Alegre & v. 54 & n. 3 & set./dez. 2009 & p. 71-89
\end{tabular}


esmerada. Estudou em Alcalá de Henares, onde recebeu o bacharelado em 1544. Também em Alcalá recebeu a licenciatura em artes (filosofia) em 1547 e a licenciatura e o doutorado em medicina em 1553, tendo entrado em conflito com seus mestres e recorrido com sucesso ao tribunal superior de doutores contra sua reprovação inicial. Em 1555 obteve a cátedra de prima na mesma universidade. Em 1572 deixou a docência na universidade de Alcalá para tornar-se médico pessoal de Felipe II, rei da Espanha. Conta-se que ascendeu a tal cargo depois de curar o rei com métodos que eram drasticamente contrários aos costumes médicos da época e que, por aquela e por outras curas miraculosas, recebeu do próprio rei a alcunha de 'Divino Valles'. Faleceu em Burgos, em 20 de setembro de $1592 .^{1}$

\section{Os sentidos internos no aristotelismo}

Sabe-se que nas tradições aristotélica e escolástica a descrição precisa do número, das funções e da localização dos sentidos internos (também conhecidos como "faculdades internas") era fundamental para compreender as doutrinas da percepção sensorial e da cognição. Portanto, qualquer dissensão entre as autoridades médicas e filosóficas poderia se constituir em forte motivo para confusão e perplexidade. Uma análise dos textos advindos do aristotelismo e dos escolásticos certamente projetará nova luz sobre a recepção da obra de Galeno, no que tange aos sentidos internos, no século XVI. Adicionalmente, tal análise demonstrará a importância e a relevância de ao menos uma parte da obra de F. Valles para a filosofia durante a Renascença e a Segunda Escolástica.

Em sintonia com o que faz Tomás de Aquino, Valles apresenta de maneira resumida a base para compreender que o número dos sentidos internos deve ser determinado pelas funções específicas desempenhadas por eles. Diferentemente de Tomás, que chega à conclusão que os sentidos internos são quatro, Valles endossa a posição de Avicena de que são em número de cinco. O primeiro é o sensus communis, cuja função principal é permitir a comparação entre os dados fornecidos por cada um dos sentidos externos, como quando compara e combina o branco e o doce. O segundo é a imaginação, ou phantasia, que começando pelas coisas percebidas, as combina e partindo delas chega a coisas que não existem, tais como montanhas de ouro ou vacas voadoras, sem, contudo

1 Dados biográficos e bibliográficos de Francisco Valles podem ser encontrados nas seguintes obras: ORTEGA; MARCOS. 1914; e SOLANA. 1941. Leitura igualmente informativa sobre a vida de Valles se encontra em COMA. Acesso em 12/03/2009. 
deixar completamente de lado o que vem através dos sentidos. O terceiro é a ratio (chamada por outros autores de ratio particularis ou de vis aestimativa) e que não apenas compõe, mas também adquire as formas das coisas a partir das formas percebidas, tais como a inimizade ou o ódio ou coisas semelhantes, os quais não vêm pelos sentidos externos. O quarto é a memória a qual é responsável por estocar as formas e por trazê-las de volta quando os objetos estão ausentes. O quinto é a reminiscência que excede a memória, pois é capaz de restaurar o que um dia se soube, mas que tinha sido esquecido, a partir das formas estocadas. $^{2}$

Visto que o contexto filosófico da obra de Francisco Valles era o da segunda escolástica, seria adequado introduzir a situação da problemática envolvendo os sentidos internos a partir da filosofia de Pedro da Fonseca. O aspecto mais relevante seria a importância dos sentidos internos para a compreensão da doutrina da abstração. ${ }^{3}$ Neste quesito, como em vários outros, Fonseca procurou seguir sempre que possível a abordagem de Tomás de Aquino e esforçou-se para demonstrar que haveria plena concordância entre as doutrinas de Tomás e de João Duns Escoto. Contudo, Fonseca também acrescentou uma contribuição pessoal à exposição do número e das funções dos sentidos internos. É exatamente neste ponto que Fonseca se serviu da obra de Francisco Valles para refutar a posição ainda corrente na sua época de que o número dos sentidos internos estava ligado à sua localização particular no cérebro. Esta posição de Fonseca não é original em sentido estrito, visto que ele procurou demonstrar de maneira cabal que tal era a posição de Aristóteles e de grande parte da tradição peripatética. Fonseca teria sido, portanto responsável por esclarecer

2 FRANCISCO Valles. Controversiarum medicarum et philosophicarum, p. 70a-70 "Profitentur enim omnes Aristotelici, cum quibus et Avicenna, esse quinque. Sensum communem, imaginationem, quae Graecis phantasia dicitur, rationem, quae aexistimativa vulgo appellatur, memoriam, et reminiscendi vim. Confirmant suam sententiam, tribuentes his omnibus diversas operationes, nam cum potentiae distinguantur per operationes: constat futurum, si actiones differunt, ut differant et potentiae, sed sensus communis (dicunt) confert res subiectas peculiaribus sensibus, ut quando album cum dulci componit. Imaginatio, ex iis quae sentiuntur incipiens, componendo, ad ea etiam quae impossibilia sunt, procedit: (qua actione, et aureos montes, si lubet, et volantes boves confingimus) tamen a rerum quae sentiuntur speciebus non recedit. Ratio non hoc solum facit: sed ab speciebus sensibilium etiam rerum species elicit, ut amicitiae, et odii, et aliarum rerum, quae in sensum non veniunt. Memoria retinet species, et res absentes recolit. Reminiscendi vis, quid memoria excidit, ab iis quae retinentur colligens, reducit."

3 Desde os comentários à Isagoge feitos por Boécio que preocupações com os sentidos internos estiveram ligadas aos temas centrais da filosofia. 
este ponto, ${ }^{4}$ mais do que propor uma nova abordagem. Neste contexto, vê-se que seria necessário propor apenas dois sentidos internos, o sensus communis e a phantasia. ${ }^{5}$

Como comprovação de sua abordagem, Fonseca argumenta que Aristóteles, no livro terceiro de sua obra De anima, a partir do capítulo terceiro apresenta em detalhes apenas estes dois sentidos internos, pois somente distingue com clareza o sensus communis e a phantasia. Já na obra De memoria, para Fonseca, Aristóteles faz a distinção entre a capacidade de recordar e a phantasia assentar exclusivamente na diferença entre ato e potência, ao passo que a conexão entre recordar e a diferença de passado não pode constituir base para uma distinção real pois a categoria de passado produz apenas distinção acidental. Tampouco pode haver distinção entre phantasia e a faculdade da estimação, pois mesmo os animais apreendem as noções de recompensa ou castigo futuros. ${ }^{6}$ Fonseca também diz que não há diferença entre o entendimento e a memória intelectiva, pois ambos estão no intelecto. ${ }^{7} \mathrm{E}$ por fim, Fonseca

4 Que esta abordagem era própria de Pedro da Fonseca fica evidente nos COMMENTARII Collegii Conimbricensis S. J. in tres libros De anima Aristotelis Stagiritae, III, c. 3, questão 1, art. 3: "Caeterum alia quaedam est opinio, etsi non antiquitati, ut quibusdam videtur, certe veritate magis consentanea, quam praeter alios nostrae aetatis nobiles philosophos, defendit Fonsecam 5. Metaphysicae c. 28. quaest. 7. sect. 4. asserens duas tantum esse potentias sensitivas internas; sensum communem, et phantasiam. Quae sententia sic tuendam a nobis est; ut dicamus sensum communem fungi iis muneribus, quae illi superius attribuimus: phantasiam vero reliquis omnibus, quae aliis sensibus internis delegabamus. Ita vero esse ex eo convincitur, quia nulla ratio cogit plures sensus constituere, ut facile videbit qui ad dilutionem argumentorum, quae plures suadebant, animum attenderit."

5 PEDRO da Fonseca. Commentariorum in libros Metaphysicorum Aristotelis v. 2, Roma, 1589, cc. 1011-1012: "Dicendum igitur, duas tantum esse interiores potentias apprehensivas corpori inhaerentes, sensum videlicet communem et phantasiam..."

6 PEDRO da Fonseca. Op. cit., c. 1012: "Quod si peculiarem librum scripsit De Memoria et Reminiscentia, non putavit tamen memorandi aut reminiscendi actum aut potentiam ab actu et potentia phantasiae distinctam esse, nisi quatenus absolutam rerum particularium cognitionem (quasi praesentium tamen, vocavit phantasiam, hinc enim phantasia tanquam ab eo, quod apparet, dicta est) eam vero, quae coniuncta est cum cognitione praeterit, appellavit memoriam et reminiscentiam, quod discrimen accidentarium est, veramque potentiarum distinctionem efficere non potest: nisi contendas dandam esse aliam potentiam sensitivam, quae res apprehendat cum differentia futuri, quod ridiculum est: apprehendunt enim vel bruta animantia pleraque sibi vel commoda, vel incommoda cum differentia futuri: ut cum canis praetento pane aut fuste, apprehensoque futuro commodo aut damno, vel adulatur, vel fugit."

7 PEDRO da Fonseca. Ibid.: "Probatur autem sententia haec de unitate phantasiae, aestimativae, et memoriae ex iis, quae superius, praesertim ad calcem superioris sectionis, diximus: et confirmatur ex iis, quae de intellectu et memoria intellectiva omnes fatemur. Dicimus enim, intellectum et memoriam unam tantum et eandem potentiam esse, quae ab actu servandi species appellatur memoria faecundusque intellectus: ut qui possit, cum opus fuerit, in actum intelligendi prodire: ab ipso autem intelligendi actu dicitur intellectus." 
aponta para o fato de phantasia e sensus communis serem distintos em localização e em função. O sensus communis está localizado na parte anterior do cérebro, onde há mais humidade e onde estão os nervos correspondentes aos sentidos externos. A phantasia, por outro lado, se situa em todo o cérebro e no cerebelo, apesar de que neste último os phantasmata são preservados melhor e exercem suas funções de maneira mais pura e tranqüila. ${ }^{8}$ Suas funções são distintas na medida em que o sensus communis somente apreende seus objetos em conexão direta com os sentidos internos e com as distinções de tempo e espaço, ao passo que a phantasia está mais distante dos sentidos externos e pode tanto apreender algo do não percebido pelos sentidos externos, como no caso da recompensa ou do castigo futuro. ${ }^{9}$

\section{Os sentidos internos e o conhecimento das coisas}

Os sentidos internos têm um papel preponderante nas doutrinas epistemológicas da antiguidade e da escolástica. O ponto em questão é o conhecido Problema dos Universais. Uma postura determinada com relação ao status ontológico dos universais acarretava uma abordagem específica do aparato sensorial e psíquico necessário para permitir a descrição detalhada do processo que vai desde as coisas particulares no mundo até os conceitos na mente humana.

No caso da visão apresentada por Fonseca e defendida por ele como sendo a mais adequada para descrever a postura peripatética, os universais têm uma existência objetiva no intelecto, a qual está fundada nas naturezas que existem nas coisas particulares, e que independem de qualquer atividade do intelecto. A primeira observação que aqui cabe é a de que Aristóteles tinha rejeitado a doutrina platônica da Reminiscência, ${ }^{10}$ pois naquela doutrina, o acesso que o intelecto tem aos

8 PEDRO da Fonseca. Ibid.: "Distinguuntur autem sensus communis et phantasia et loco, et officio. Loco quidem, quia sensus communis in anteriori parte magni cerebri collocatus est, ubi abundat humidum, et in quem locum omnium particularium sensuum nervuli, quasi in communem radicem concurrunt: phantasia vero in toto reliquo magno cerebro, et in cerebello inest: tametsi in cerebello melius conservat."

9 PEDRO da Fonseca. Op. cit., c. 1013: "Officio autem distingui has potentias, luculenter et copiose ostendit Aristoteles secundo capite libri tertii De anima, text 136 cuius argumentis haec duo addi possunt. Unum, quod sensus communis praesentia tantum et loco, et tempore, simulque cum sensibus externis apprehendat obiecta: phantasia vero etiam loco distantissima, et cessantibus ante longo tempore sensibus externis. Alterum, quod communis sensus sensata duntaxat, ut externi cognoscat, phantasia vero ex sensatis insensata eliciat, et ex aliis in alia, si perfacta sit, discurrat."

10 A fim de compreender toda a extensão da rejeição da teoria da Reminiscência platônica por Aristóteles, recomenda-se a leitura de GIFFORD. 1999. 
universais precede qualquer contato com as Formas nas coisas, pois o intelecto tem contato com os universais no Mundo das Formas. Aristóteles afirma com toda veemência que os universais não possuem qualquer existência real fora das coisas particulares no mundo. A questão central então se torna como descrever as atividades dos sentidos, externos e internos, e do intelecto de tal maneira que não haja espaço para postular qualquer contato entre o intelecto e os universais que anteceda o contato dos sentidos com as coisas no mundo. Este é o domínio da psicologia filosófica, pois é necessário descrever com riqueza de detalhes a fisiologia da percepção sensorial e a corresponde doutrina da cognição.

O tema do presente artigo se restringe ao contexto em que a contribuição de Valles se mostra decisiva e, portanto, basta uma exposição sintética dos tópicos. Um fato digno de menção é a opção que Fonseca faz pela abordagem tomista da doutrina aristotélica da cognição, ou seja, daquela exposição pormenorizada que se encontra nas obras de Tomás de como o intelecto interage com os sentidos para conhecer as coisas. Neste contexto, aparece claramente o hilemorfismo de Tomás, especialmente no tocante à posição do Aquinate de que a pessoa humana é um todo composto por componentes materiais e espirituais. ${ }^{11} \mathrm{Um}$ ponto bastante relevante da abordagem tomista é que os componentes materiais, ou seja, a dimensão corpórea do ser humano são necessários para receber a forma material das coisas, visto que somente o igual pode perceber o igual a si, assim é a parte material da pessoa humana que pode receber a forma material das coisas. Por outro lado, os universais que não são materiais, somente podem ser recebidos por algo que seja não-material, que no caso do ser humano é o intelecto. ${ }^{12} \mathrm{~A}$ importância destes pontos ficará clara logo a seguir.

A relevância da discussão sobre o número e as funções específicas dos sentidos internos e do papel que têm na cognição está diretamente ligada à consistência da concepção metafísica de determinado autor. Boécio, por exemplo, postulava que os sentidos percebem a realidade de maneira confusa, contudo o intelecto tem a tarefa de discernir os atributos essenciais das coisas e distingui-los dos componentes acidentais

11 Ainda segue vivo o debate acerca da atualidade da psicologia filosófica de Aristóteles. Alguns tentam ver em Aristóteles uma espécie de funcionalista ante littera. Para mais detalhes a respeito do debate, recomenda-se a leitura de NUSSBAUM; RORTY. 1992, principalmente os seguintes textos: BURNYEAT. 1992; NUSSBAUM; PUTNAM. 1992; COHEN. 1992. Também interessantes são as seguintes obras: EVERSON. 1997; e MODRAK. 2001.

12 A leitura tomista da psicologia filosófica de Aristóteles foi estudada por vários autores. Alguns dos mais recentes e pertinentes são: KRETZMANN. 1992; STUMP. 1999. Contudo, nem todos pensam que as ideias de Tomás ainda são atuais, conforme se pode verificar em KENNY. 2001. 
das mesmas. ${ }^{13}$ Complementarmente, autores como Avicena viram a necessidade de postular um sentido interno adicional, conhecido em Latim como vis aestimativa, porque, em sua maneira de ver, as naturezas comuns das coisas eram intrinsecamente não-materiais, sem, contudo ser imateriais. Em função disto, Avicena divisou um sentido interno cujos objetos próprios fossem não-materiais, porém também não-imateriais, sendo que este sentido interno somente poderia ser a vis aestimativa. ${ }^{14}$ Tomás de Aquino, por outro lado, defendeu a opinião de que teria que haver tantos sentidos internos quanto os necessários para possibilitar a satisfação das necessidades dos animais. Portanto, dependendo das funções essenciais a serem executadas pelos animais com vistas a aumentar e preservar suas melhores chances de sobrevivência haveria a necessidade de postular o numero de sentidos internos correspondente ao desempenho de tais funções. ${ }^{15}$ Mais ainda. Visto que João Duns Escoto postulou para os universais uma unidade real, sua abordagem do número dos sentidos internos exigiu um altíssimo grau de complexidade. Por outro lado, Guilherme de Ockham não viu qualquer necessidade de todo um aparato interno para explicar o conhecimento, pois para ele bastariam os sentidos externos e o intelecto uma vez que haveria uma distinção muito simples entre as categorias de substância e de qualidade. Os sentidos externos percebem substâncias particulares, e como tudo o que há são as substâncias particulares, os sentidos externos e o intelecto perceberiam as substâncias e as qualidades particulares. Visto que autores como Fonseca adotaram as posições de Boécio, Tomás e Escoto, a posição de Fonseca com relação aos sentidos internos tem que ser compatível com as abordagens de cada um deles.

Tal tarefa nem sempre era simples, pois além de compreender e explicar a abordagem daqueles autores, Fonseca teve que levar em conta

13 BOÉCIO In Isagogen Porphyrii commentorum editionis secundae, p. 164-165: "Sed animus cum confusas res permixtasque in se a sensibus cepit, eas propria vt cogitatione distinguit. Omnes enim huiusmodi res incorporeas in corporibus esse suum habentes sensus cum ipsis nobis corporibus tradit, at vero animus, cui potestas est et disiuncta componere et composita resolvere, quae a sensibus confusa et corporibus coniuncta traduntur ita distinguit ut incorpoream naturam per se ac sine corporibus in quibus est concreta speculetur et videat. Diversae enim proprietates sunt incorporeorum corporibus permixtorum, etsi separentur a corpore".

14 Um texto muito interessante sobre o significado da vis aestimativa em Avicena é BLACK. 1993. Sobre os sentidos internos em Avicena, recomenda-se a leitura de ATTIE FILHO. 2000 e ID. 2007.

15 TOMÁS de Aquino. Summa theologiae [31708] Ia q. 78 a. 4 co.: "Respondeo dicendum quod, cum natura non deficiat in necessariis, oportet esse tot actiones animae sensitivae, quot sufficiant ad vitam animalis perfecti. Et quaecumque harum actionum non possunt reduci in unum principium, requirunt diversas potentias, cum potentia animae nihil aliud sit quam proximum principium operationis animae". 
o fato de que Boécio, Tomás e Escoto apresentaram suas visões sobre o número e as funções dos sentidos internos em contextos particulares nos quais havia determinado tipo de concepções da anatomia e da fisiologia cerebral humana. Aquelas concepções certamente influenciaram a maneira com que aqueles autores explicaram o status ontológico das coisas e impuseram sérias limitações às suas abordagens das doutrinas da percepção e da cognição, ou seja, à sua visão da psicologia humana. A tarefa de Fonseca era apresentar a opinião correta dos autores que o antecederam de uma maneira plenamente compatível com a abordagem mais avalizada da anatomia e da fisiologia humana disponível em seus dias.

Ao nível da fisiologia do cérebro humano, houve importante progresso quando André Vesálio, normalmente conhecido como Andreas Vesalius (1514-1564) ${ }^{16}$ argumentou no capítulo 06, do livro VII de sua magistral obra De humani corporis fabrica de 1543 que não era verdade que sentidos internos tais como a memória e a phantasia estavam localizados em partes diferentes dos ventrículos cerebrais, como tinham pensados vários autores medievais. Primeiro, porque suas dissecações mostram acima de qualquer dúvida que havia quatro cavidades cerebrais e não três como aqueles autores medievais pensavam, ou seja, havia as partes direita e esquerda e a parte posterior do cérebro e o cerebelo. ${ }^{17}$ Para alguns autores medievais havia o ventrículo anterior, o ventrículo médio e o ventrículo posterior do cérebro. Estas partes sucediam uma à outra em linha reta. Tal doutrina era atribuída a Galeno e parece ter influenciado vários dos principais autores médicos medievais. Segundo, Vesálio apontou para o fato de que todos os seus contemporâneos negavam a possibilidade de que macacos, cães, cavalos, ovelhas, bovinos e outros animais, tivessem alguma das mais importantes faculdades da alma humana e atribuíram apenas ao ser humano a faculdade da razão. Para tal, os contemporâneos de Vesálio postulavam o caráter único do cérebro humano. Vesálio, porém, encontrou em suas dissecações pouquíssimas diferenças em estrutura entre o cérebro humano e o daqueles animais, exceto quanto ao tamanho. A faculdade da razão tal distintiva dos seres humanos não

16 Para dados biográficos de Andries van Wesel, também conhecido como Andreas Vesalius Bruxelensis, desde seus estudos de artes em Lovaina, onde dentre outras coisas ele aprendeu Latim e Grego, passando por sua formação em medicina em Paris, e chegando até sua atividade docente em Lovaina e Pádua, com atenção especial para suas contribuições para o estudo da anatomia humana, recomendase a leitura de WEAR. 1995.

17 ANDRÉ Vesálio. De humani corporis fabrica, p. 633: "Ventriculorum cerebri numero is asscribitur, qui cerebello dorsalisque medullae communis est, ac quartus etiam dicitur, tres nanque in cerebro ventriculos, Herophilum imitati, collocamus. Ac unum quidem in dextra cerebri parte, alterum in sinistra et tertium in cerebri, seu duorum primorum ventriculorum medio recensemus". 
poderia ser materialmente localizada nos ventrículos cerebrais e teria que ser atribuída apenas à livre escolha de Deus. A deliberação divina livre escolheu distinguir algo que materialmente seria virtualmente indistinto. ${ }^{18}$

Isto quer dizer que uma parte bastante significativa de todas as discussões anteriores sobre os sentidos internos, ou seja, a correspondência entre função, importância e localização distinta de phantasia, memória, faculdade cogitativa ou vis aestimativa, teve que ser abandonada de maneira irrevogável.

O verdadeiro impacto daquele desenvolvimento somente pode ser percebido ao se ter em mente que no centro da doutrina da localização distinta dos sentidos internos em diferentes partes do cérebro está a pressuposição de que também os sentidos internos tinham que seguir o princípio aristotélico de que para cada faculdade sensorial externa havia um órgão sensorial correspondente. Complementarmente, a opinião de que a fisiologia humana era intrinsecamente distinta da fisiologia dos outros animais não era o único traço relevante naquele debate. Autores como Avicena, Averróis, Alberto Magno e Tomás de Aquino desenvolveram a doutrina dos sentidos internos de maneira muito ampla a fim de adaptar e atualizar a filosofia antiga às suas visões particulares da pessoa humana. A ordem dos sentidos internos deveria seguir os diferentes estágios da cognição, com a conseqüência de que quanto mais fundo fosse a localização de um sentido interno particular, maior seria a sua importância. A questão central é portanto em que medida as taxonomias dos sentidos internos propostas por aqueles autores poderiam

18 ANDRÉ Vesálio. Ibid., p. 636: "Hunc itaque in gignendo animali spiritu usum ventriculis asscribere neutiquam vereor, at de principis animae facultatum in cerebro sedibus (quamvis etiam has illi qui hodie theologi vocari gaudent, omnia impune sibi licere arbitrati, assignent) nihil enarrandum duco. Quando omnes quibuscum vivimus, praecipuas principis animae vires simiis, canibus, equis, ovibus, bobus, eiusque generis animantibus penitus adimunt, et ut caeteras taceam, soli homini ratiocinandi facultatem, eamque omnibus quantum ab ipsis capere possum, parem tribuunt: quamvis interim homines nullo sinu illa animalia superare inter dissecandum conspicimus: neque solum numerus idem est, at caetera omnia (si modo molem et temperamenti ad iustitiam integritatem excipias) inter se sint similima. Liceat itaque vel illorum hominum gratia me ab alio ventriculorum usu inquirendo abstinere: neque vel hic Galeni placiti meminisse, qui tertio de Hippocratis et Platonis dogmatibus, medium ventriculum: in libris autem de Partium usu postremum, principalissimum esse docet. Ac proinde Deo rerum omnium opifici hymnos canentes, gratias agemus, quod nobis rationalem animam, quam cum angelis (ut Plato etiam male tractatorum philosophorum haud immemor innuebat) communem habemus, largitus fuerit, cuius beneficio si modo fides adsit, aeterna illa foelicitate fruemur, quando animae sedem ac substantiam non corporum resectione, aut nostra corporeo vinculo obruta ratione inquirere necessarium erit. Nam is qui vera est sapientia, nos non hoc generabili et putrescibili corpore amplius, sed spirituali suoque quam similimo constantes, edocebit". 
sobreviver à derrocada da concepção medieval da anatomia do cérebro que estava em voga quando aquelas taxonomias foram propostas.

Em todo o caso, havia espaço suficiente para uma revisão pormenorizada de cada elemento que comporia a compreensão exata do número e das funções dos sentidos internos. Visto que o De anima continuava sendo amplamente lido, traduzido e comentado, as obras produzidas em psicologia filosófica depois das bombásticas conclusões de Vesálio tinham que levar em conta as dificuldades resultantes da obra deste médico renascentista.

Além dos avanços no campo da anatomia, principalmente em função de uma melhor compreensão das obras e das idéias de Galeno e de Hipócrates, também digno de menção é o fato de que os jesuítas eram assíduos leitores e comentadores do De anima de Aristóteles. Este interesse era na verdade compartilhado pelas outras ordens religiosas e por outros filósofos e médicos em geral. Apenas para citar as obras produzidas no período em que Francisco Valles desenvolvia seus estudos e sua prática médica, inclusive sua visão particular da psicologia filosófica, temos os Commentaria una cum Quaestionibus in III libros de anima de Francisco Toledo, publicados em Veneza em 1574; os Commentarii collegii conimbricensis S. I. in tres libros de anima Aristotelis Stagiritae publicados pelos conimbricenses em 1598; os comentários manuscritos de Fonseca aos três livros do De anima produzidos em torno de 1559/1560; e os Commentaria una cum quaestionibus in libros Aristotelis de anima de Francisco Suárez produzidos no final do século XVI, porém publicados em 1621.

Estes textos e idéias produzidos pelos jesuítas do século XVI com relação aos De anima de Aristóteles foram e ainda são objetos de interesse para vários autores. A psicologia dos primeiros jesuítas tem sido descrita como uma consciente forma de aristotelismo que tinha plena consciência das dificuldades inerentes à tarefa de tentar reconciliar uma leitura fiel de Aristóteles, uma filosofia cristã verdadeira e a razão natural. Mais ainda. A psicologia dos primeiros jesuítas é analisada em termos do projeto educacional que se tornou marca registrada da Companhia de Jesus desde os seus primórdios, principalmente no que respeita aos manuais de estudo produzidos pelos jesuítas, com seu estilo comentarístico característico, o qual teve um papel central no desenvolvimento das idéias psicológicas do período em questão. ${ }^{19}$ Os autores mais recentes que se interessam por aqueles textos dos jesuítas do século XVI dão especial ênfase ao fato daquele período ser descrito como 'segunda escolástica', a qual pode ser definida como um movimento que "surgiu a partir das

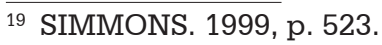


cátedras tradicionais de metafísica na via Thomae e na via Scoti", ${ }^{20}$ e que por isto tem que ser levado em consideração que obviamente haveria "um certo distanciamento da postura aristotélica", ${ }^{21}$ visto que tal movimento estava mais interessado em racionalizar a filosofia cristã do que em expor as idéias de Aristóteles em sua forma mais pura. Os mesmos autores não deixam de enfatizar também o fato de que o caráter de continuidade da tradição aristotélica nunca deve ser subestimado. ${ }^{22}$ Igualmente ressaltado tem sido o fato de que o caráter nascente da Companhia de Jesus significou que eles não ficaram limitados pela necessidade de defender a visão de algum autor medieval em particular, como por exemplo, foi geralmente o caso de dominicanos e franciscanos que tinham já uma tradição de autores de suas ordens para estudar e defender, de maneira que cada um dos jesuítas pôde desenvolver uma opinião multifacetada e própria. ${ }^{23}$

Há uma pluralidade de avaliações entre os autores recentes que estudam a psicologia dos primeiros jesuítas, contudo é possível identificar alguns traços comumente atribuídos a eles, pois a psicologia dos primeiros jesuítas foi apresentada em manuais; fazia referências aos escritos metafísicos dos autores escolásticos; expressava de maneira explícita sua adesão ao aristotelismo e à teologia cristã; demonstrando sempre criatividade e marcas claramente distintivas.

Notável é o fato de que os jesuítas parecem ter-se dado conta de que o estudo da psicologia aristotélica era parte indelével de sua missão educativa. ${ }^{24} \mathrm{E}$ visto que não somente se propuseram a estudar e a comentar as idéias psicológicas de Aristóteles e dos autores escolásticos, mas também a imprimir os seus manuais tratando da scientia de anima, a sua influência nas gerações seguintes é notável.

Algo que a literatura recente sobre a psicologia dos primeiros jesuítas deixa sem resposta é a pergunta sobre o porquê da tentativa daqueles primeiros jesuítas de construir um corpo de conhecimento científico abrangendo metafísica, psicologia e as outras ciências, dentre as quais a teologia. Que os primeiros jesuítas tinham uma visão sistemática da filosofia fica evidente pelo estudo de suas obras e foi notado por autores como Alison Simmons e Dennis Des Chenne. Estes últimos, porém, não fazem qualquer esforço para apresentar evidências que corroborem esta conclusão. Aqui não é possível ir a fundo neste debate, contudo é possível

20 KESSLER. 1988, p. 507. Tradução nossa.

${ }^{21}$ KESSLER. 1988, p. 508. Tradução nossa.

22 Novamente se observa que Alison Simmons não aceita o preconceito de que os jesuítas eram profundamente heterodoxos. A este respeito, ver SIMMONS. 1999, p. 534-535.

23 KESSLER. 1988, p. 511.

24 DES CHENE. 2000. 
trabalhar com a hipótese de que faltou a estes autores recentes algum dado importante. Este elemento que permitiria completar o quadro geral de maneira satisfatória seria justamente a importância do fato de que Fonseca inseriu a discussão da psicologia aristotélica em seu comentário ao livro V da Metafísica. Naquele trecho Fonseca destaca o fato de que a base metafísica para a sua psicologia filosófica e para a solução dos principais problemas associados aos Predicáveis é o correto entendimento da filosofia aristotélica. É também naquela parte da obra de Fonseca que ele diz, "Franciscus Vallesius, vir sane doctus nec solum de Medicinae arte ac peritia, sed de nobiliori quoque Philosophia benemeritus". ${ }^{25}$

Portanto, parece evidente que é necessário estudar as contribuições de Francisco Valles para bem compreender o debate sobre o número e as funções especificas dos sentidos internos e para criar as condições que permitam identificar os contornos precisos nos quais se desenvolveram as doutrinas da percepção e da cognição dos primeiros jesuítas e dos autores dos séculos posteriores.

\section{Francisco Valles, o 'Galeno Espanhol'}

Como visto acima, Valles trata da questão do número preciso e da função peculiar de cada um dos sentidos internos, ou faculdades da alma como ele os chama, em seu Controversiarum Medicarum et Philosophicarum, livro II, capítulos 22 e 23. Para estabelecer o contexto preciso, Valles antes tinha tratado da anatomia e da fisiologia do cérebro e, depois de falar das faculdades naturais de adquirir (trahens), de reter (retinens), de transformar (alterans) e de excretar (excernens ou expellens), de maneira geral, ele se dedica a discutir as faculdades de guardar (attinere) as notitiae. Sua preocupação é determinar onde estas últimas faculdades deveriam ser localizadas no cérebro e quais seriam as suas atividades peculiares e compará-las aos sentidos externos, que são seus instrumentos próprios. ${ }^{26}$

Depois de apresentar de maneira sintética a doutrina tradicional dos sentidos internos, Valles se propõe a examinar as diferentes atividades de cada um dos sentidos para poder decidir se realmente são distintas umas das outras. ${ }^{27}$ É neste momento que ele decide discutir se a postura

25 PEDRO da Fonseca. Op. cit., col. 1009.

${ }^{26}$ FRANCISCO Valles. Op. cit., p. 70a: "Quaestiones ad animalium facultatum notitiam attinentes, opportunum est iam attingere. Sunt fero facultates hae duplices. Quaedam in ipso cerebro, quod prima illarum sedem esse diximus, resident, et a medicis rectrices appelantur: quaedam peculiares, quae scilicet peculiarium sunt actionum, et peculiaribus instrumentis operantur, ut visus, odoratus, auditus".

27 FRANCISCO Valles. Op. cit., p. 70": "Videntur vero haec omnia differre, quare, cum quinque modi oper[ati]onum sint, videntur et quinque potentiarum species fore". 
usualmente atribuída a Galeno está correta. ${ }^{28}$ Conforme dito acima, o século XVI viu um enorme progresso nos estudos galênicos devido ao fabuloso número de edições, em Grego e em Latim, das obras daquele médico da antiguidade.

Galeno postula a sua divisão tripartida dos sentidos internos da alma humana ${ }^{29}$ baseado em sua apresentação do que acontece quando há alguma disfunção da mente, como nos casos de delírio, pois os erros que a mente pode cometer neste caso são basicamente três, e, portanto, o número de sentidos internos deve também ser três. Em primeiro lugar pode haver um problema na cognição, por exemplo, quando alguém pensa estar vendo flautistas num canto da casa quando de fato não há ninguém lá. Em segundo lugar pode haver um problema na ratio, por exemplo, quando alguém nada vê de fora do comum, mas ainda assim calcula de maneira equivocada. Em terceiro lugar pode haver um problema na memória, por exemplo, quando alguém sabe o que está vendo, sabe o nome do que está vendo, mas não consegue lembrar-se daquilo. Os sentidos internos seriam, portanto a faculdade cogitativa, a ratio e a memória. ${ }^{30}$

A posição de Galeno parece conflitar diretamente com a posição de Avicena. O médico e filósofo persa, porém, pensou poder explicar a diferença entre sua abordagem e a de Galeno dizendo que este último tinha tratado três sentidos como se fossem apenas um, pois disfunção da memória acarretava os mesmos problemas para os sentidos da imaginação e para a reminiscência e que, desta maneira, do ponto de vista médico se poderia falar em apenas três sentidos internos. Valles discordou veementemente daquela estratégia e disse que ao dizer aquilo Avicena fez dissipar completamente a distinção entre memória,

28 Para dados complementares sobre a popularidade das obras de Galeno no século XVI, recomenda-se a leitura de CONRAD; NEVE; NUTTON; PORTER; WEAR. 1995, p. 253.

29 Para uma apresentação pormenorizada de como Galeno logrou reconciliar Platão e Hipócrates, a fim de preservar a divisão tripartida da alma humana, recomenda-se a leitura de HANKINSON. 1991; e ID. 2006.

30 FRANCISCO Valles. Op. cit., p. 70": "Galenus res iam esse dicit, imaginationem, rationem, et memoriam, quas vocavit principem, animi partem $\eta \vartheta \gamma \varepsilon \mu$ ovıкóv, octavo De Usurpatium capite sexto. Quod probat libello De differentia symptomatum per species phrenitidis, hoc argumento: quacunque recticum facultatum laesa, contingit hominem insanire necessario: quandoquidem princeps animae pars est, ergo tot sunt potentiae, quot laesonum modi, et insaniae sed huius tres tantum sunt species (trifariam enim tantum potest laedi mens: vel quoniam homo errat, in cognitione, ut Theophilus, qui tibicines se videre in domus angulo dicebat, quos videbat nullos; vel quoniam cum, in hoc nihil erret, tamen prave ratiocinatur, ut qui cum vasa vitrea cognosceret et propriorum nominum recordaretur, tamen cognita proiieciebat; vel quoniam laeditur memoria) cum ergo tres tantum sint laesionum modi, constatat tres solum esse potentias". 
imaginação e reminiscência. Portanto, Valles adota a taxonomia de Galeno dos três sentidos internos e ainda assim adota a divisão em cinco atividades diferentes. ${ }^{31}$

$\mathrm{Na}$ opinião de Valles, a abordagem de Galeno era perfeitamente compatível com a de Aristóteles no De anima e no De memoria. ${ }^{32} \mathrm{E}$ considerando a questão do número dos sentidos internos como resolvida, Valles dedica o restante do capítulo 23 ao tema adjacente da localização

31 FRANCISCO Valles. Op. cit., p. 70" "Avicenna huius argumenti solutionem hanc imaginatus, est, laesionem sensus communis necessario comitari laesionem phantasiae; et laesionem reminiscendi, memoriae; atque proinde medicorum non interesse plurimum quam trium potentiarum meminisse. Sed cur ita fiat, ut semper cum sensu imaginatio, et cum memoria laedatur remiscendi vis, si diversae sunt facultates; neque dixit, neque potest dicere. Quare hoc etiam argumento est, non inevidenti tres tantum esse has facultates et eas actiones, quae illis tribuuntur non esse quinque, sed tres tantum species, et quinque operationum modos. Nam actio, sensus et actio phantasiae, hoc uno differunt: quod sensus componit sensibilium species, in praesentia; imaginatio componit has easdem in absentia. Constant vero, ut haec non sit speciei differentia. Quare non sunt duae operationum species, sed eiusdem actionis duo modi. Quocirca unius sunt facultatis. Reminisci praeterea memoriae est ops, cum se reflectit in seipsam. Non enim est memoriae opus, ut multi putant, solum species retinere (ita enim non esset potentia cognoscens, sed servans tantum species) sed memoriae est recordari rerum absentium, ut res sunt actae ergo imaginatio est sensus; et reminisci memoriae ulterior quidam motus, non actio diversa. Quod non tantum Galenum sensisse, sed et Aristotelem monstrabo: quidquid dicat Avicenna. Tertio libro De Anima cap 3 cum de imaginationis essentia multa disputasset Aristoteles ad finem capitis addit. Si igitur nihil aliud praeter imaginationem habet ea quae dicta sunt, sitque id ipsum quod diximus, imaginatio motus profecto fuerit, sensus iam operantis. Quae verba oscitanter omnes praetereunt, constat tamen illis nihil aliud significari, quam imaginationem actionem esse eiusdem potentiae, cuius est sensus actus. Sed hanc eandem potentiam quae sensus est, cum rebus praesentibus operatur, sensum esse, cumque vera componit: cum vero falsa, phantasiam. Memoria, dicente eodem Aristotele libello De memoria et reminiscentia, differt a sensu, quod memoria in absentia rerum operatur cum sensu temporis; phantasia operatur in absentia rerum, sed sine sensu temporis, cum enim lectiones fingimus, aut disputationes ad arbitrium, imaginamur; sed cum disputasse nos heri, legisse nudius tertius cognoscimus, redordamur; quia cum cognitione rerum temporis sensus coniungimus. Reminiscimur memoria se in seipsam reflectente, ergo eiusdem potentiae motus sunt, recordari et reminisci".

32 FRANCISCO Valles. Op. cit., p. 71ª: "Videtur ergo sententia haec Galeni cum verbis Aristotelis plurimum convenire, quae si ut scripsimus intelligatur, nihil videtur habere difficile, saltem ea argumenta, quibus plures esse quam tres, nonnulli contendunt, mihi nullam inferunt difficultatem, videtur aliquanto difficilius, quod Galenus libello secundo De motu musculorum inquit: Pars enim animae quae imaginatur, quaecunque ea sit, haec eadem recordari videtur. Quare si eadem pars imaginatur et recordatur: imaginatio et memoria unica est potentia. Caeterum hoc ita interpretandum est: Videtur imaginandi potentia recordari; quoniam pro ratione imaginationis quae praecessit, subsequitur firma aut debilis recordatio quoniam cum fortis imaginatio fit, insignes impressiones rerum fiunt, quae memoriam deinde firmiter permutant. Differunt tamen recordatio et imaginatio, differentia illa, quam invenit Aristoteles: quod scilicet memoria operatur cum sensu temporis. Sed de numero harum facultatum, haec sunt satis". 
cerebral dos sentidos externos. Valles estava interessado na localização dos sentidos internos nos ventrículos cerebrais.

A opinião mais comumente aceita no meio médico contemporâneo de Valles era de que a sede da imaginação era o ventrículo frontal, a seda da ratio era o ventrículo central e a sede da memória era o ventrículo posterior. Avicena, dentre outros, defendeu tal localização baseando-se nos efeitos dos danos a cada uma daquelas partes, o que supostamente era a opinião de Galeno. Valles, porém, indicou que tal doutrina não se encontra na obra de Galeno. De fato, para Galeno, os três sentidos internos têm sua sede no cérebro, mas não há atribuição de uma localização particular para nenhum deles. ${ }^{33}$

O fato notável em tudo isso é que o conhecimento que Valles tinha da obra de Galeno era tão profundo que ele pôde refutar um erro que ainda persistia quatro séculos mais tarde na obra conhecida de $\mathrm{H}$. Wolfson e que foi atacada posteriormente por Christopher Green. ${ }^{34}$ Wolfson defende que a localização ventricular dos sentidos internos tem sua origem nas obras de Galeno. Valles refutou tal postura apontando para o fato de que os que erroneamente a atribuem a Galeno o fazem baseando-se exclusivamente naquela passagem em que Galeno fala da divisão dos sentidos internos decorrente dos três diferentes tipos de delírio. A localização diferente no cérebro decorreria de uma composição diversa da substância cerebral, o que permitiria que uma parte fosse danificada, ou seja, que houvesse dano a um sentido interno particular, enquanto

${ }^{33}$ FRANCISCO Valles. Op. cit., p. 71a-71": "Communis omnium fere medicorum opinio est, imaginationis sedem esse anteriorem cerebri partem; rationis medium ventriculum; memoriae postremum. Aetius sermone secundo Tetrabibli secundi capite secundo ita scripsit: Proinde anteriori cerebri parte laesa, imaginatio solum laeditur; medio vero cerebri ventriculo laeso, ratio pervertitur; posteriore autem circa occipitium parte laesa, perit memoria, et cum ipsa omnino etiam reliquae duae facultates. Haec Aetius, Avicenna Fen prima primi doctrina sexta, capite quinto, eandem hanc sententiam aperte scripsit. Itaque his autoribus censent plerique medicorum, tres facultates, quarum nuper meminimus differre locis, eoque nunc apponenda esse remedia syncipiti, nunc occipiti, nunc medio ventriculo in illarum laesionibus. Sed tamen ego non video, ex quo Galeni loco collegerint hanc locorum differentiam. Esse quidem has facultates in cerebro, e vitiata quacunque illarum capiti esse apponenda medicamenta, monstrat Galenus multis in locis, quae non paulo antem retulimus. Sed hanc partium cerebri differentiam (quod ego legerim) docet nullibi. Quin potius contrarium videtur deduci ex non multis illius locis. Primum octavo libro de usu partium capite sexto sub unico hoc nomine $\eta \vartheta \gamma \varepsilon \mu$ ovıkó $v$ comprehendit tres potentias animales, et eas in cerebro dicit residere, nulla particularum cerebri facta distinctione".

34 WOLFSON. 1973 é certamente um texto antigo, porém de certa maneira ainda pode ser considerado um clássico com relação à discussão dos sentidos internos. Wolfson diz, na página 254, que a tal localização dos sentidos internos foi apresentada por Galeno no texto On the affected parts. Contudo, esta atribuição é questionada por GREEN. 2003, p. 134-135. 
que as outras partes permaneceriam saudáveis, ou seja, que os demais sentidos internos continuassem funcionando normalmente. ${ }^{35}$ Para Valles, tal distinção entre a composição das diferentes partes do cérebro não era necessária, visto que a diversidade de atividades dos sentidos internos não está relacionada com uma localização distinta em um dos ventrículos; portanto, os sentidos internos operam em todo o cérebro, possivelmente sendo mais ativos em alguma parte do cérebro, sem, contudo restringirse a apenas uma localização particular. ${ }^{36}$

35 FRANCISCO Valles. Op. cit., p. 71 imponendum auxilia desumpsisse Galenum, qualem illi dicunt, ex facultate quae laeditur in phrenitide. Sed quaecunque phrenitis sit, decimo tertio Methodi capite vigesimo primo, auxilia infundit in futuram coronalem; sumpta indicatio ne a structura membri, quasi ex ipius membri partibus nulla alia indicatio desumi possit. Praeter haec quae quaeso tanta diversitas est in modo substantiae partium ipsius cerebri? Aut quae tam diversa temperamenta, quae hanc facultatum differentiam persuadeant? Dicitur etiam a Galeno secundo de motu musculorum loco illo, quem improxima quaestione aduximus; si itaque insignes impressiones rerum in imaginotionibus acceperit, conservat perpetuo. Quod ita interpretati sumus Confirmari memoriam, interim dum sit fortis imaginatio, quod non video quomodo fieret, nisi imaginatio et memoria eodem in loco opererentur. Sed dicent qui contrariae opinionis sunt, (ullum enim aliud video ab ea opinione forte argumentum) qua ratione in eadem parte possint esse tres facultates, et ut una laedatur aliis illaesis? Illis enim facile est huic quaestioni, qua quaeritur, quomodo laedatur, una illarum, illesis aliis, respondere, dicentibus, cum laeditur sola pars anterior, laeditur sola imaginatio; eum solus ventriculus medius, sola ratio".

${ }^{36}$ FRANCISCO VALLES. Controversiarum medicarum et philosophicarum, p. 71 ${ }^{\mathrm{b}}-72^{\mathrm{a}}$ : "[T]amen nobis qui negamus hanc locorum differentiam, vel saltem non asserimus, ut pote nulla cogente ratione, necesse est facultates has diversis eiusdem partis temperamentis tribuere, ut nihil mirum sit, unam laedi illaesis aliis; quemadmodum in toto ventriculo sunt trahendi, retinendi, alterandi, expellendi virtutes; non tamen quacunque illarum laesa, laeduntur omnes. Nam alteratio fit calore cum humiditate; retentio et tractio quadam siccitate; expulsio etiam, sed minori, quo fit, ut possit per se quaecunque illarum laedi propria laesione. Sed haec evadent multo clariora ex tractatione de causis symptomatum. Dicent secundo, oportere ex nostra opinione, ut nulla esset ventriculorum cerebri dignitatis differentia nam cum omnes virtutes sint in partibus omnibus; aeque principales videntur fore omnes partes, quod tamen contra Galenum octavo de usu partium, ubi postremum aliis praefert; et tertio de locis partibus capite septimo, ubi ita scripsit: ac primum ipsius instrumentum, tum ad sentiendi actiones omnes, tum ad eas quae a consilio et voluntate prodeunt, spiritum esse, qui in ipsius ventriculis, maximeque potremo continetur quamvis non contemnendus sit medius; perinde quasi non praestantis simus fit, multae enim rationes non adducunt ad hunc, et a duobus anterioribus avertunt. Hoc loco Galenus ultimum reliquis omnibus, et medium duobus anterioribus praefert. Sed neque hoc ex principatu facultatum, quae in hoc aut illo ventriculo resident, fieri puto; quemadmodum illi interpraetantur. Sed omnis facultates in toto cerebro operari; minime vero in anterioribus ventriculis, maxime in postremo; in medio, medio modo, quemadmodum est alterandi facultas in toto ventriculo, viget vero maxime in fundo. Sed quando satis diximus de rectricum facultatum sede". 


\section{Conclusão}

O debate sobre o número, as funções e a localização precisa dos sentidos internos desempenhou um papel preponderante para as doutrinas da percepção e da cognição, desde Aristóteles até o final do século dezesseis. Todavia, depois dos grandes desenvolvimentos no campo da anatomia humana durante o Renascimento, havia a necessidade de repensar tudo o que Aristóteles e seus mais famosos comentadores tinham escrito a respeito. Uma dificuldade adicional era descobrir maneiras para reconciliar as visões dos sentidos internos vindas da tradição peripatética com as contribuições do médico Cláudio Galeno. Em ambos os casos, verifica-se a relevante contribuição de Francisco Valles, que através de suas obras influenciou o debate sobre os sentidos internos e da correta interpretação da obra de Galeno em fins do século XVI. O interesse pela obra de Valles certamente seguirá vivo e poderá contribuir até mesmo para o estudo da história da filosofia e da anatomia antiga, medieval e renascentista.

\section{Referências}

ANDRÉ Vesálio. De humani corporis fabrica. 1543.

TOMÁS de Aquino. Summa theologiae. Disponível em http://www.corpusthomisticum. org/iopera.html Acesso em 13/10/2008.

ARISTÓTELES De anima (apresentação, tradução e notas de Maria Cecília Gomes dos Reis). São Paulo: Editora 34, 2006.

AVICENNA Liber De anima seu sextus de naturalibus I-III. Lovaina/Leiden: Peeters/ Brill, 1972. $\overline{\text { Brill, } 1968 .}$

Liber De anima seu sextus de naturalibus IV-V. Lovaina/Leiden: Peeters/

ATTIE FILHO, M. O intelecto em Ibn Sinã (Avicena). Cotia, SP: Ateliê Editorial, 2007.

. Os sentidos internos em Ibn Sinã (Avicena). Porto Alegre: EDIPUCRS, 2000.

BLACK, D. L. "Estimation (Wahm) in Avicenna: the logical and psychological dimensions". Dialogue XXXII, 1993, p. 219-258.

BOÉCIO In Isagogen Porphyrii. Corpus Scriptorum Ecclesiasticorum Latinorum: 48. Vindobonae: Tempsky, 1906.

BURNYEAT, M. "Is an Aristotelian philosophy of mind still credible? (A Draft)". In: NUSSBAUM, M. C. \& RORTY, A. O. (eds.) Essays on Aristotle's De anima. Oxford: Clarendon Press, 1992, p. 15-26

COHEN, S. M. "Hylomorphism and functionalism". In: NUSSBAUM, M. C. \& RORTY, A. O. (eds.) Essays on Aristotle's De anima. Oxford: Clarendon Press, 1992, p. 57-73.

COMA, J. M. R. Biografía. Dr Francisco Valles de Covarrubias "el divino". In: http:// www.gorgas.gob.pa/museoafc/loscriminales/biografias/valles.html Acesso em 12/03/2009. 
COMMENTARII Collegi Conimbricensis Societatis Jesu in tres libros De anima. Coimbra: A. Mariz, 1598.

CONRAD, L. I.; NEVE, M.; NUTTON, V.; PORTER, R. \& WEAR, A. The Western Medical Tradition - 800 BC to AD 1800. Cambridge: Cambridge University Press, 1995.

DES CHENE, D. Life's Form: Late Aristotelian Conceptions of the Soul, Ithaca, 2000.

EVERSON, S. Aristotle on perception. Oxford: Clarendon Press, 1997.

FRANCISCO de Toledo. In libros De anima in Opera omnia. Hildesheim/Zurich/New York: Olms, 1985.

FRANCISCO Suárez. Commentaria una cum quaestionibus in libros Aristotelis De anima - Comentarios a los libros de Aristóteles sobre el Alma, t. 1 Madrid: Sociedad de Estudios y Publicaciones, 1978; t. II Madrid: Labor, 1981; t. III Madrid: Fundación Xavier Zubiri, 1991.

FRANCISCO VALLES. Controversiarum medicarum et philosophicarum. Veneza, 1591.

GALENO. Galeni De symptomatum differentia liber tertius, Gullielmo Copo Basileiensi interprete (Galeni Operum Omnium). Veneza, 1541.

GIFFORD, M. "Aristotle on platonic recollection and the paradox of knowing universals: Prior Analytics B.21 678-30". Phronesis XLIV/1, 1999, p. 1-29.

GREEN, C. "Where did the ventricular localization of mental faculties come from?" Journal of History of the Behavioral Sciences, 39(2), 2003, p. 131-142.

HANKINSON, R. J. "Galen's anatomy of the soul". Phronesis XXXVI/2, 1991, p. 197-233.

. "Body and soul in Galen". In: KING, R. A. H. (ed.) Common to Body and Soul. Berlin/New York: Walter de Gruyter, 2006, p. 232-258.

KENNY, A. Essays on the Aristotelian tradition. Oxford: Clarendon Press, 2001.

KESSLER, E. "The intellective soul”. SCHMITT, C. et al. The Cambridge History of Renaissance Philosophy. Cambridge/New York/New Rochelle/Melbourne/Sydney: Cambridge University Press, 1988, p. 485-534.

KRETZMANN, N. \& STUMP, E. (eds.) The Cambridge companion to Aquinas. Nova Iorque: Cambridge University Press, 2006.

KRETZMANN, N., KENNY, A. \& PINBORG, J. The Cambridge history of later medieval philosophy. Cambridge: Cambridge University Press, 1997.

. "Aquinas's philosophy of mind", Philosophical Topics 20/2, 1992, p. 77-102.

MODRAK, D. K. W. Aristotle's theory of language and meaning. Cambridge: Cambridge University Press, 2001.

NUSSBAUM, M. C. \& RORTY, A. O. (eds.) Essays on Aristotle's De anima. Oxford: Clarendon Press, 1992.

NUSSBAUM, M.; PUTNAM, H. "Changing Aristotle's mind". In: NUSSBAUM, M. C. \& RORTY, A. O. (eds.) Essays on Aristotle's De anima. Oxford: Clarendon Press, 1992, p. 27-56.

ORTEGA, E. \& MARCOS, B. Francisco de Valles (El Divino). Madrid: Imprenta Clásica Española, 1914.

PEDRO da Fonseca. Commentariorum in libros Metaphysicorum Aristotelis. v. 2. Roma: 1589. 
SIMMONS, A. "Jesuit Aristotelian Education: the De Anima Commentaries". In: O'MALLEY, J. W.; BAILEY, G. A.; HARRIS, S. J. \& KENNEDY, T. F. (eds.) The Jesuits: cultures, sciences, and the arts 1540-1773. Toronto: University of Toronto Press, 1999, p. 522-537.

SOLANA, M. Historia de la filosofía española, v. II: Época del Renacimiento. Madrid: Asociación Española para o progreso de las ciencias, 1941.

STUMP, E. "Aquinas on the mechanisms of cognition: sense and phantasia". In: FRIEDMAN, R. L. \& EBBESEN, S. (eds.), Medieval analyses in language and cognition, Historisk-filosofiske Meddelelser 77, Copenhagen, 1999, p. 377-395.

WEAR, A. "Medicine in Early Modern Europe, 1500-1700". In: CONRAD, L. I.; NEVE, M.; NUTTON, V.; PORTER, R. \& WEAR, A. The Western medical tradition - 800 BC to $A D$ 1800, Cambridge, 1995, p. 273-280.

WOLFSON, H. A. Studies in the history of philosophy and religion. v. 1. Cambridge: CUP, 1973. 